\title{
3 Research Square

\section{An Interesting Result of a Qualitative Research: Academic Exhaustion Barrier to Professionalism in Medical Students}

\section{Zohrehsadat Mirmoghtadaie ( $\nabla$ mirmoghtadaie@sina.tums.ac.ir)}

Tehran University of Medical Sciences https://orcid.org/0000-0002-3267-9121

Noushin Kohan

virtual university of medical sciences

Soleiman Ahmady

Medical Education School,Shahid Beheshti University of Medical Sciences,second Affiliated of Virtual University of Medical Sciences

Research article

Keywords: Medical Education, Medical Student, Professionalism, Qualitative Research

Posted Date: June 1st, 2019

DOl: https://doi.org/10.21203/rs.2.9983/v1

License: (c) (i) This work is licensed under a Creative Commons Attribution 4.0 International License. Read Full License 


\section{Abstract}

Background: Clinical education is a vital part of the curriculum in medical education. Some studies showed that dominant values changed during education, and some negative values might replace positive ones. In this regard, this study aimed to explore various aspects of the barrier to professionalism in clinical medical education. By describing the experiences that interns had as educational outcomes during their years of education, and in the clinical setting of their patients, efforts were made to obtain an image of what was happening and to take some steps towards reducing these shortcomings and move towards training more efficient physicians with higher qualifications by providing necessary strategies to educational planners. Method: This was a qualitative study conducted with the content analysis method. The research population consisted of the students of Iran's two most important medical schools in 2018. A total of 34 interviews with 23 participants were done, each lasting 30 to 90 minutes and data analysis performed with Atlas ti7 software. Results: Two hundred forty-eight original codes were extracted from the research data, which were classified under the theme of "Academic Exhaustion" and the four following categories: "stressful environment, "human conflict," "Poor Inter professional collaboration," and "emotional exhaustion." Conclusion: What was understood from all categories was called "Academic Exhaustion." According to the results of this study, it can be admitted that having full knowledge of the factors influencing professionalism from the viewpoint of stakeholders can improve the environmental and organizational conditions to prevent professional misconduct.

\section{Background}

Clinical education is a vital part of the curriculum in medical education and plays a significant role in shaping basic skills and professional capabilities of students [1] .Clinical education aims to provide opportunities for students to associate theoretical information with practical facts and acquire experiences through their presence by impatiens' beds [2].

The process of students' adaptation to the real environment of their profession is not done easily, because the complicated and unpredictable nature of clinical experiences makes it difficult for students to achieve their intended goals, and this can provide stressful situations for them [3]. A clinical education environment is an interactive network for the elements in clinical practice that affects the outcomes of the students' clinical learning. $[3,4]$. Hence, improving the quality of clinical education can lead to the training of competent and qualified students in the clinical field [5]. As clinical education is the primary source of learning for students' attitudes, values and norms, experiences of medical students can present the most critical characteristics of clinical education.

What they have learned and what they have not learned as well as what have been their feelings are the things students can express more than any other group. Since ethics is the center of future developments [6], medical universities are responsible for training physicians who would be able to improve the health of the community. Therefore, becoming a physician is equal to gaining a new identity in life, and the physician starts his/her medical profession by accepting some responsibilities and having a specific set 
of characteristics [1]. Professionalism means having the attitude and behaviors that include some characteristics such as selflessness, trustworthiness, affection, proper communication, respect, responsibility, excellence and leadership [7,8].

The Accreditation Council of Graduate Medical Education and the Board of Specialized Medical Sciences of the United States established six main competencies for Resident Specialists; one of them is a commitment to professional principles [9]. For development and excellence of commitment to professional principles, occurred errors must be identified and behaviors that reflect the commitment to professional principles need to be strengthened $[10,11]$. From Sachs' perspective, professionalism has two "ethical" and "technical" aspects. The ethical aspect is the same as a teacher's performance, with the aim of serving the community and responding to its needs, and the technical aspect refers to having a decent performance as well as skills [8], the prerequisite of which is to acquire wide and complex knowledge through academic education [12]. The developments of science and technology in the 20th century, which have led to the advancement of health and medical care [13, 14]. Today, teaching professionalism is greatly emphasized in universities around the world. [12, 14- 15]. Professionalism values are expected to be formed during education in medical schools and also during patient care, but some studies showed that the values that students had when they entered the university underwent changes during their studies [15], and some negative values might be formed instead of positive ones. Although professionalism concepts are sometimes taught in clinical medical education, it is mainly institutionalized by the role of teachers and others.

Despite great efforts by medical professors to teach professional values to the learners, sometimes contents that are not consistent with these values are learned, and their ultimate effects are even observed at the community level as the following threats to medical professionalism: changing personal and professional values of the graduates through formal education, lack of accountability, noncommitment to respond to community issues such as patients' age, culture, sex, and disabilities, poor quality of service delivery, and inconsistency of university outcomes with the needs and expectations of the community [16]. Many of these problems can be considered a violation of ethical principles by universities and non-compliance with high ethical standards [17]. Today clinical experts focus on the outcomes of technology development (medical equipment and facilities) more than on human relationships. They are gradually forgetting the main commitment of their profession, which is compassionate and empathic care, recognizing the patients and respecting them as human beings, as the cornerstone of medical ethics and disturbance in customer-centeredness is especially observed nowadays. This can be due to financial aspects, differences in physician's and patient's influence, and the entry of trade into the medical profession, which has gradually led to the elimination of ethical conduct in clinical medical practices [18]. The main prerequisite for achieving professionalism is the recognition of Factors and barriers that are effective in this process.

The present study aimed to explore barriers of professionalism in clinical medical education. 
The critical question of this study is "what are the experiences of medical students from the barrier to professionalism in clinical education?"

\section{Methods}

The research population consisted of the students of two critical medical schools in Iran who had attended clinical wards for at least six months in 2018. The participants were selected from among the students who had been in an internship for at least six months in clinical wards. The purposive sampling started and continued until data saturation, i.e., the lack of receiving new information. The total number of participants in the study reached 23. The duration of the interviews was 30 to 90 minutes, and a total of 34 interviews were conducted. Qualitative interviewing is generally regarded as an effective way of understandings about experiences and the meanings people attach to them. In this research, some interviews were repeated because the researcher was looking for opportunities to understand different dimensions or seek clarification or additional information about issues raised in earlier interviews. Additional interviews also were needed because a less familiar concept was found in the first interview. Repeated interviewing led to increases in the amount of information reported repeat interviews to provide opportunities to capture something about events, experiences, and perceptions over time.

Total interview time lasted 35 hours and 28 minutes. After analyzing each interview, the next interview was conducted. There was an interview guide that included four questions on the desired concept. The questions were as follows:

1. What does the word professionalism remind you of?

2. What do you think about the meaning of professionalism in the clinical setting?

3. Can you tell us about your experiences in the environment?

4. What factors do you think affect professionalism or professional misconduct in a clinical setting?

During the interviews, query questions such as "Can you explain more?" or "What do you mean?" were also asked. We used the conventional qualitative content analysis method in the analyses, which is a research method for subjective interpretation of the content of written data. In this method, categories are extracted directly from textual data, and codes and themes are identified through a systematic classified process. $[19,20]$.

The analysis process was performed by summarizing the meaning units and converting them into codes, subcategories, and categories (Table 1) and using the content analysis method with Graneheim and Landman approach. Data analysis performed with Atlas ti7 software. [19, 20-21]. In the data interpretation, obvious and hidden contents were taken into consideration.

\section{Context}

Iran's 7-year medical education program consists of 3 consecutive stages. An initial 2.5 years pre-clinical education, commonly known as "basic science" stage, three years of clinical training and a final 1.5 years 
of "internship" which is supervised medical practice at teaching hospitals. Clinical education at Iranian medical universities is a significant issue. Professionalism is a standard of interest to the medical faculty.

In many medical schools, centers called "professional commitment centers "Which carries out the training, monitoring and evaluation of students and professors.

\section{Trustworthiness of qualitative data}

Numerous frameworks have been developed to evaluate the rigor or assess the trustworthiness of qualitative data [22] and strategies for establishing credibility, transferability, dependability, and Confirmability. In this study, the credibility of the qualitative findings was ensured by using member check and immersion techniques as well as the ongoing engagement of the researchers with the data. Then, in order to complete the data and examine the transferability of the findings, in addition to individual interviews, two focus groups of 5 and six other students who were not interviewed individually were asked about the consistency of the findings with their experiences. To increase the reliability of the data, the long-term work with the research subject, the observers' review and controlling the findings with the participants regarding the extent of reflecting their experiences were used. The principles of confidentiality of information and informed consent for interviewing and recording the conversations were observed as well. The right to withdraw from the research at any time was one of the ethical considerations that were observed, too.

\section{Results}

A total of 23 students participated in 34 interviews. The mean age of interview participants was 25.5 years. The distribution of sampling criteria is presented in Table 2 .

Two hundred forty-eight original codes were extracted and Classified under the theme of "academic exhaustion" and four categories as follows: "stressful environment', 'human conflict," "inter professional collaboration," and "emotional exhaustion." Each of these subjects had some subcategories (Table 3).

\section{1-Stressful Environment}

From the viewpoint of the participants in this study, environmental factors were among the factors affecting professionalism. The extracted subcategories included the "inappropriate Duty overwork," "Unfriendly tutoring," and "Environmental structure."

\section{1-1-Duty Overwork}

The participants in this study believed that in a clinical setting, one could behave ethically so that the relationship between the patient and the physician would be appropriate. In such a situation, instructors 
and students could observe all human considerations and the patients' dignity. Here are some related quotes from the participants in this study:

Participant 20: "When I enter the ward, I get terrified. How to deal with too many patients destroys me. How many sick people for a medical student?"

\section{1-2- Unfriendly Tutoring}

In the opinion of the participants in this study, a safe psychological environment would lead to the effectiveness of education and observation of professional principles.

Participant 13: "I can act professionally when others behave me well. When the instructor and the patients always belittle you, how can you work in peace and do it right?"

\section{1-3- Ambiguous Position}

The participants in the research believed that the feeling of belonging and personal satisfaction could be very useful in working professionally or not.

Participant 8: "I belong to somewhere, and I feel responsible for it, and this will give me maximum satisfaction."

\section{2- Human Conflict}

The participants in the study considered the following three sub-categories as the factors affecting professional performance: "professional Satisfaction," "communication skills" and "interpersonal interactions."

\section{2-1- Professional Satisfaction}

The participants believed that in a clinical environment, one could act properly when there was Professional satisfaction, and this is also related to the job position. Participant 1: "I do not know exactly what I should do there. My duties and internship goals were not already specified, so I do not know what to do and how."

\section{2-2- Communication Skills}

Participant 9: "Student reprimand in front of the patient demolishes their entire personality. They cannot work right anymore when they are not treated properly."

\section{2-3-Interpersonal Interactions}

Participant 19: "We can see in most internship departments that doctors and nurses are doing their job separately as if they are not in the same area at all. The only thing they have in common is their clients lying down on the hospital beds." 


\section{3- Poor Inter professional collaboration}

\section{3-1- Team Working}

One of the constructive themes of effective performance from the viewpoints of medical students is human factors. In this study, the participants paid particular attention to the team working and cultural barriers.

Participant 12: "In clinical settings, each works on his/her own, while the treatment team should act as a single person to improve the system."

Participant 3: "Internship settings are good places to learn what's called the hidden curriculum, but if the nurses, doctors and the treatment team are in the same chain."

\section{3-2- Cultural Barriers}

The participants in this study believed that humans had different cultures, and therefore, respect for all of them, regardless of gender and ethnicity, was necessary.

Participant 1: "From the very beginning, the students must know that all human beings are respectful, and cultural differences are some part of the structure of interactions.

\section{4- Emotional Exhaustion}

\section{4-1- Inadequate Motivation}

Participant 13: "I do not like to go to different departments for patients' files. I like the shift to end up sooner to get out of the ward."

\section{4-2- Incompatibility with Clinical Setting}

Participant 7: "We, medical students, have no place especially in the hospital; not a proper category and not even a place to rest."

\section{Discussion}

Medical students cite communication, respect, patient care, medical knowledge and skills as the hallmarks of professionalism. The results of this study showed that professionalism is affected by various environmental, human and organizational factors. Clinical education planning forms the essential part of medical education for creating necessary capabilities and skills in medical students.

This research showed that the quantity of health providers is essential to implementing professionalism; because the high number of patients affected the quality of care. In separate studies conducted by Marcum and Barbe and Tse, they concluded that the heavy workload of their health providers it is very tired them and it is necessary to adjust the proportion of patients to the number of health providers. 
[23].The research has been conducted in countries such as the United States, China, and Colombia, which shows that there is not a current dilemma is our country. Any problem in clinical education may encounter the efficiency and outcomes of this part of education with barriers, one of which is tension [24].

During studying, medical students have much stress which can have adverse effects on their learning and clinical success. Some of the stressors in clinical practice include high numbers of patients, lack of clinical experience, lack of communication with nursing staff, lack of decision-making power in executive works, long hours of internship and inconsistency between caregivers and physicians and students' unwillingness to Clinical work [25]. One of the most stressful environmental factors was the Ambiguous position of the hospital. This factor, in the view of medical students, causes disturbance and discomfort. So far, various studies have been done to find effective components for the comfort of users of various buildings. Analysis of the impact and the role of building users' characteristics (gender, age, and country of origin), physical and non-structural issues related to the building, such as interior space, type of building, color, spatial arrangement, are only part of a variety of research in this area. The area that is consistent with this research is known to cause ineffective stress people. [26].

Professional satisfaction was one of the subcategories that were placed on the category of human conflict and could be a barrier to professionalism. Professionalism goes through the formation of a professional identity. Multiple factors within and outside of the educational system affect the formation of an individual's professional identity [27].

Communication weakness can have a negative effect on performance [28]. This is consistent with the results of the recent research. Collaboration between nurses and doctors, team working, joint decision making on health issues, follow-up of patient care plans to solve its problems is essential.

The effects of inter-professional collaboration can be seen to reinforce positive attitudes towards other members and link them up. Although gender and ethnic differences are factors that affect professional behaviors, the researcher did not find research that directly linked to an agent-based relationship with professional behavior. This result in the present study can show cultural differences in Iran, and class divisions which will be followed by it.

Also, finally, emotional exhaustion Obtained from research. Emotional exhaustion is a job problem that causes negative and pessimistic tendencies towards the referrers and colleagues and reduces the daily activities of employees.

Research suggests that motivation in medical students depends on the accurate feedback and the effective supportive system [29]. In this study, it was also consistent with other studies that poor supportive systems caused the misconduct of medical students. In the present study, some participants pointed out this issue and related clinical unaccountability to unfamiliarity with the clinical environment, and familiarity with the clinical environment and its compatibility with it predispose sense of belonging to the environment. Most students in the first day of a clinical day find stress in a new environment. The 
clinical instructor should devise special measures for the first day in order to make the learners familiar with the clinical environment and feel comfortable in it [30].

What was understood from all the categories was called "Academic Exhaustion." Academic exhaustion refers to the students' feeling of fatigue due to the demands and requirements of studying, having a pessimistic feeling without interest in one's assignments, and a feeling of inadequacy as a student. Academic exhaustion affects students' commitment to the college and their degree of participation in health affairs. It also provides grounds for reducing the academic performance of students and increasing their concern about making mistakes in their assignment. Identifying all these factors affecting professional performance, either individual or environmental and organizational, can be useful in preventing professional misconduct in the medical conditions of our community, where the entry of some unmotivated and uninterested people in the medical profession has been facilitated.

\section{Conclusions}

Having full knowledge of the factors influencing professionalism from the viewpoint of medical students, educational authorities can improve the environmental and organizational conditions to help medical students prevent professional misconduct in order to take steps to improve the health of the community.

Research Limitations: Since the data collection tool was the interviewers, this study is not error-free, like other qualitative research, because sometimes the thoughts, beliefs of the interviewers influence the research subject and the process of data collection. The research was attempted to go through the right process by putting the comments of the researchers between parentheses while collecting and analyzing the data.

\section{Declarations}

\section{Declarations}

Competing Interests: The authors declare that they have no competing interests.

Acknowledgment: We would like to thank all participants for their cooperation.Furthermore, we would like to acknowledge all experts involved in developing the program.

Funding: the Vice-Chancellor of the Virtual University Research made substantial contributions to the conception and design of this study and was substantially involved in the acquisition, analysis and interpretation of data. The Vice-Chancellor of the Virtual University Research took the lead in drafting and revising the manuscript and gave final approval of the version to be published.

Author's contributions: Zohreh made substantial contributions to the conception and design of this study and was substantially involved in the acquisition, analysis and interpretation of data. Zohreh took the lead in drafting and revising the manuscript and gave final approval of the version to be published. 
Nushin made substantial contributions to the conception and design of this study and was involved in the acquisition, analysis and interpretation of data. Nushin assisting in revising the manuscript and gave final approval of the version to be published. Soleiman made substantial contributions to the conception and design of this study and was involved in the acquisition, analysis and interpretation of data. Soleiman assisting in revising the manuscript and gave final approval of the version to be published. All authors read and approved the final manuscript.

Availability of data and materials: The datasets used and/or analyzed during the current study are available

from the corresponding author on reasonable request.

Consent for publication: Not applicable.

Ethics approval and consent to participate: The study has been submitted to the ethics committee of the virtual University of medical sciences which allowed to carry out this study and ethical considerations were observed (obtaining informed consent, confidentiality of information and secrets of the participants, the right to withdraw from the research at any time, the right to demand the tape and its transcript).

\section{References}

1- Elcigil A, Yildirım Sari H. Determining problems experienced by student nurses in their work with clinical educators in Turkey. Nurse Educ Today. 2007; 27(5): 491-498.

2-Lowenstein AJ, Bradshaw MJ. Fuszard's innovative teaching strategies in nursing. 3rd ed. Boston, MA: Jones and Bartlett; 2004.

3-Chan DSK.Validation of the clinical learning environment inventory. West J Nurs Res August. 2003; 25(5): 519-532.

4- Lucas J, Wilson- Witherspoon P, Baxley EG. Walking the balance BEAM: the art and science of becoming a successful clinical teacher. Fam Med. 2002; 34(7):498-9.

5-Lowenstein AJ, Bradshaw MJ. Fuszard's Innovative Teaching Strategies in Nursing. 3rd ed. Maryland: An Aspen Publication; 2001.

6- Horton K, Tschudin V, Forget A. The value of nursing: a literature review. Nurs Ethics. 2007; 14(6):71640

7- Cohen JJ. Professionalism in medical education: an American perspective: from evidence to accountability. Med Educ 2006 Jul; 40(7): 607-17.

8-Goldstein EA, Maestas RR, Fryer-Edwards K, Wenrich MD, Oelschlager AA, Bernstein A, et al. Professionalism in medical education: an institutional challenge. Med Educ 2006; 81(10): 871-6. 
9-Accreditation Council of Graduate Medical Education. Program director guide to the common program requirements. Version 2; 2007. [Citd 2017 Apr 20]. Available from:

http://www.acgme.org/Portals/0/PDFs/commonguide/CompleteGuide_v2\%20.pdf

10-Frohna JG.The American Board of Pediatrics and the Association of Pediatric Program Directors. Teaching and Assessing Professionalism: A Program Director's Guide. 1st Ed; 2008.

11-Van Mook WN, van Luijk SJ, O'Sullivan H, Wass V, Harm Zwaveling J, Schuwirth LW, et al. The concepts of professionalism and professional behavior: Conflicts in both definition and learning outcomes. Eur J Intern Med. 2009; 20(4): e85-9.

12-Coulehan J. Viewpoint: today's professionalism: engaging the mind but not the heart. Acad Med 2005 Oct; 892-8:10)80

13-Wagner P, Hendrich J, Moseley G, Hudson V. Defining medical professionalism: a qualitative study. Medical education. 2007 Mar 1; 41(3):288-94.

14-Whitcomb ME. Medical Professionalism: can it be taught? Acad Med 2005; 80(10): 883-4.

15-Glicken AD, Merenstein GB. Addressing the hidden curriculum: understanding educator professionalism. Med Teach 2007; 29(1): 54-7.

16-University of Toronto Governing Council. Standards of Professional Practice Behaviour for all Health Professional Students. 2008. [Cited 2015January16] Available

from:http://www.governingcouncil.utoronto.ca/Assets/Governing+Council+Digital+Assets/Policies/PDF.

17-Swing SR. The ACGME outcome project: retrospective and perspective. Med Teach. 2007; 29(7): 64854.

18-Gelhaus P. The desired moral attitude of the physician :( I) empathy. Med Health care philos. 2012; 15(2): 103-13.

19-Hsieh HF, Shannon SE. Three approaches to qualitative content analysis. Qual Health Res. $2005 ; 15$;( 9) $1277-88$.

20-Spannagel C, Gläser-Zikuda M, Schroeder U. Application of qualitative content analysis in userprogram interaction research. Qualitative Social Research. 2005; 6(2)

21-Graneheim UH, Lundman B. Qualitative content analysis in nursing research: concepts, procedures, and measures to achieve trustworthiness. Nurse Educ Today. 2004; 24(2): 105-12

22-Lincoln YS, Guba EG. Establishing trustworthiness. Naturalistic inquiry. 1985; 289:331 
23- Tse KY, So WK. Nurses' perceptions of preoperative teaching for ambulatory surgical Patients. J Adv Nurs 2008; 63(6): 619-25

24- Lambert V, Glacken M.Clinical Support roles: a review of the literature. Nurse Educ Pract2004, 83-177 : (3) 40

25-Lambert V, Glacken M.Clinical Support roles: a review of the literature. Nurse Educ Pract2004, 83-177:( 3) 40

26-Jager AJ, Tutty MA, Kao AC. Association between physician tension and identification with medicine as a calling. InMayo Clinic Proceedings 2017 Mar 1 (Vol. 92, No. 3, pp. 415-422). Elsevier

27-Cruess RL, Cruess SR, Boudreau JD, Snell L, Steinert Y. A schematic representation of the professional identity formation and socialization of medical students and residents: a guide for medical educators. Academic Medicine. 2015 Jun 1; 90(6):718-25

28-Eric J Thomas, J Bryan Sexton, Robert L Helm Reich Discrepant attitudes about teamwork among critical care nurses and physicians. Crit Care Med. 2003 Mar; 31 (3), pp: 956-9. [My paper

29- Bridges DR, Davidson RA, Odegard PS, Maki IV, Tomkowiak J Poor Interprofessional collaboration: three best practice models of interprofessional education. Med Educ Online. 2011; 16.

30-Gaberson KB, Oerman MH. Clinical Teaching Strategies in Nursing. 3nd Ed. New York: Springer Publishing Company; 2010.

\section{Tables}

Table 1: An example of meaning unit, code, subcategory and category

\begin{tabular}{|c|c|c|c|}
\hline meaning unit & code & subcategory & category \\
\hline $\begin{array}{l}\text { When instructors and patients belittle you frequently, how } \\
\text { can you work quietly and right? }\end{array}$ & $\begin{array}{l}\text { humiliating } \\
\text { experiences }\end{array}$ & $\begin{array}{l}\text { Unfriendly } \\
\text { tutoring }\end{array}$ & $\begin{array}{l}\text { Stressful } \\
\text { environment }\end{array}$ \\
\hline
\end{tabular}

Table 2- Distribution of sampling criteria in participant 


\begin{tabular}{|c|c|c|c|}
\hline Participant & Sex & Age & University Location \\
\hline $\mathrm{P} 1$ & male & 24 & Isfahan University of Medical Science \\
\hline $\mathrm{P} 2$ & male & 25 & Shahid Beheshti University of Medical Science \\
\hline P3 & male & 27 & Isfahan University of Medical Science \\
\hline $\mathrm{P} 4$ & Female & 30 & Isfahan University of Medical Science \\
\hline P5 & Female & 28 & Shahid Beheshti University of Medical Science \\
\hline P6 & Female & 25 & Isfahan University of Medical Science \\
\hline P7 & Female & 25 & Shahid Beheshti University of Medical Science \\
\hline P8 & Female & 27 & Shahid Beheshti University of Medical Science \\
\hline P9 & Female & 24 & Shahid Beheshti University of Medical Science \\
\hline $\mathrm{P} 10$ & Female & 24 & Shahid Beheshti University of Medical Science \\
\hline $\mathrm{P} 11$ & Female & 25 & Isfahan University of Medical Science \\
\hline $\mathrm{P} 12$ & Female & 26 & Isfahan University of Medical Science \\
\hline $\mathrm{P} 13$ & Female & 24 & Shahid Beheshti University of Medical Science \\
\hline $\mathrm{P} 14$ & Male & 25 & Shahid Beheshti University of Medical Science \\
\hline $\mathrm{P} 15$ & male & 25 & Isfahan University of Medical Science \\
\hline $\mathrm{P} 16$ & male & 25 & Shahid Beheshti University of Medical Science \\
\hline $\mathrm{P} 17$ & Male & 25 & Isfahan University of Medical Science \\
\hline P18 & male & 24 & Isfahan University of Medical Science \\
\hline P19 & male & 25 & Shahid Beheshti University of Medical Science \\
\hline $\mathrm{P} 20$ & male & 27 & Isfahan University of Medical Science \\
\hline P21 & Female & 25 & Shahid Beheshti University of Medical Science \\
\hline P22 & Female & 26 & Shahid Beheshti University of Medical Science \\
\hline P23 & Fevmale & 26 & Shahid Beheshti University of Medical Science \\
\hline
\end{tabular}

Table 3: The main theme, categories and subcategories of the study 


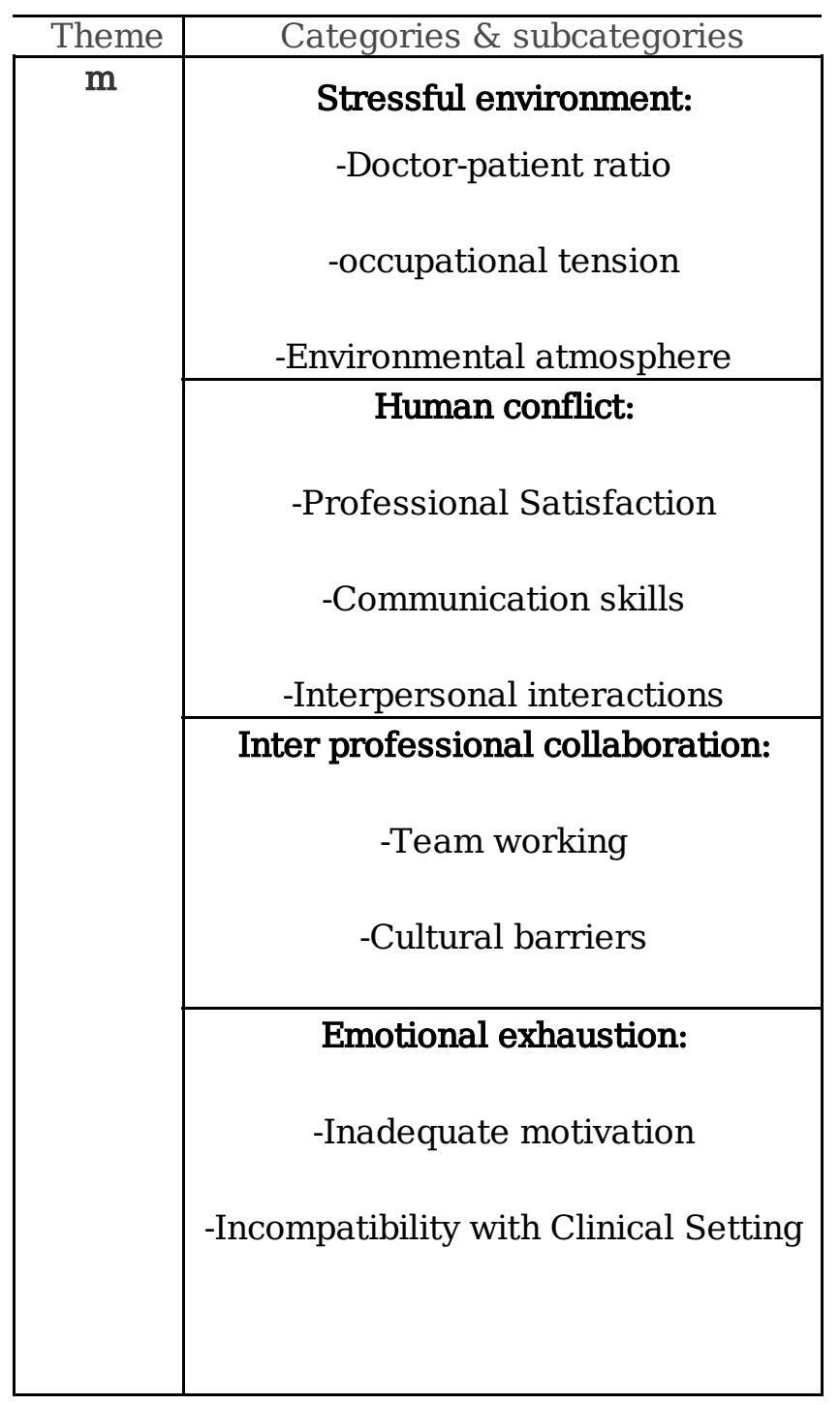

